\title{
Spatial methods for analysing large-scale artefact inventories
}

\author{
Andrew Bevan*
}

Finds distributions plotted over landscapes and continents, once the mainstay of archaeological cultural mapping, went into a lengthy period of decline when it was realised that many were artefacts of modern recovery rather than patterns of their own day. What price then, the rich harvest of finds being collected by modern routine procedures of rescue work and by metal-detectorists? The author shows how distribution patterns can be validated, and sample bias minimised, through comparison with maps of known populations and by presenting the distributions more sharply by risk surface analysis. This not only endorses the routine recording of surface finds currently undertaken in every country, but opens the door to new social and economic interpretations through methods of singular power.

Keywords: distribution maps, geo-referencing, risk surface analysis, multivariate regression, Portable Antiquities Scheme, Norman coinage, Iron Age coinage, Domesday population

\section{Introduction}

Archaeology is experiencing its own modest version of a wider 'big data' phenomenon, with the arrival of broadly disseminated, rapidly escalating quantities of geo-referenced digital information, gathered at spatial scales ranging from the microscopic to the truly continental. Sticking solely with national or trans-national inventories, some good archaeological examples are various large-scale databases for radiocarbon dates (e.g. Steele \& Shennan 2000), archaeobotanical or faunal samples (e.g. Shennan \& Conolly 2007) and cultural heritage sites (e.g. national monument records), to name but a few. Metal artefacts are slowly also receiving such treatment and three important and inter-related UK examples are discussed in more detail below. Part of this emphasis also reflects an increasing priority on 'open' data across all sections of academic research, commerce and the public sector, particularly with commitments to less restrictive copyright, interoperable formats and joined-up approaches to digital archiving, all again part of a wider trend in several countries (e.g. Bevan in press).

Archaeological datasets certainly do not represent the same order of computational and data-mining challenge raised by those gathered in other research sectors, where the flow of digital information from mobile devices, social networking sites, web browsers, medical records, remote sensing, etc. require innovative storage and management solutions even before they are analysed (this being the proper meaning of 'big data' as used elsewhere). However, the wide-ranging, geo-referenced and/or progressively licensed inventories that

* Institute of Archaeology, University College London, 31-34 Gordon Square, London WC1H OPY, UK (Email: a.bevan@ucl.ac.uk) 
are now increasingly common in archaeology should still shift our goalposts and enlarge our interpretative ambitions. Small- and medium-grain studies will rightly continue to be a core archaeological focus, but there are now some new opportunities if we re-engage with the large-scale in a systematic way.

One major challenge that remains, however, is to find a set of robust methods that not only grapple with the inevitable issues of sample bias, but also go beyond such problems to achieve traction on more interesting questions relating to human behaviour in the past. This paper explores some ways to assess such data via spatial statistical methods. As case studies, it considers three important and related efforts at recording metal finds across England and Wales: the Portable Antiquities Scheme (PAS), the Celtic Coin Index (CCI) and the Corpus of Early Medieval Coin Finds (EMC). It begins by characterising some well-known biases present in the PAS dataset, but argues strongly that we can now work very productively with such large-scale inventories. Thereafter, the second and third sections of this paper consider two coin databases that are either almost wholly integrated into the PAS (CCI) or complementary to it (EMC), and emphasises: a) the importance of comparing artefact inventories with measures of contemporary regional demography, and b) the utility of spatial methods that explicitly account for differential recovery effects via 'relative risk' surfaces. A final section draws some general conclusions about where future analytical emphasis might be placed.

\section{A national perspective on portable artefacts}

The Portable Antiquities Scheme (PAS) is a national experiment in the voluntary recording of archaeological artefacts that have been found by members of the public. It is a highly innovative response to the UK's unusual historical and legislative framework for dealing with newly-found precious (and now base) metal antiquities, especially those discovered via the use of metal detectors (the use of the latter being prohibited in many other countries, see Bland 2005). The scheme has involved an advisory body of artefact specialists, a technical infrastructure for widespread digital dissemination and the work of 35-40 liaison officers in different parts of the country. The latter, in particular, cooperate with members of the public, local institutions, metal-detecting societies, etc. to locate, photograph and identify individual finds regardless of their ultimate destination as public or private property.

At the time of writing, the PAS database documents some 450000 findspots and c. 720000 individual objects, of which 89 per cent can be located to within a kilometre grid square or better and 65 per cent to within a $100 \times 100 \mathrm{~m}$ square or better. There are a few instances of wrongly recorded locations, whether by mistake or because of the finder's intent to deceive, but an intensive effort of cross-checking and problem-flagging nonetheless makes this a fairly reliable and transparent spatial dataset, especially for medium- to coarse-grained analysis (Richards et al. 2009; Walton 2010; Brindle 2011; see also Robbins in prep.). One further criticism sometimes made of the PAS data is that it suffers from well-known recovery biases and a number of these are explored below. In a sense, however, our ability to be so explicit from the outset about certain recovery problems is a major strength of the PAS rather than a weakness; in contrast, the same clarity and consistency is rarely achievable for 
Heritage Environment Records, despite the fact that they are often seen as a gold standard for regional- or national-scale inventories. With this caveat in mind-that we should not consider clear-cut recovery bias as an insurmountable weakness, but rather as a potential strength if properly handled-how do we go about making more formal assessments of the post-taphonomic factors influencing the spatial distribution of PAS finds? An obvious approach is correlative modelling via multivariate regression. In archaeology so far this has usually been used to consider the probability of finding archaeological sites in certain parts of the landscape (e.g. Verhagen \& Whitley 2011), but similar methods can be applied to consider distributions of artefacts.

Put simply, how correlated are PAS finds with patterns of modern land use, distances from present-day communities, the presence or absence of soils conducive to detection, etc? One way to approach this issue is to lay a $1 \times 1 \mathrm{~km}$ grid across England and Wales and model varying find intensity against equivalent resolution mappings of various environmental, administrative and cultural variables. This chosen scale of analysis is deliberately coarser than the typical recording precision of the PAS finds, and also coarser than the minimum intended resolution of the possible covariate data (of which more below). It is also useful to select only those PAS metal finds that are: a) found by metal detector, and b) recorded since May 2003, during which the PAS has been up and running throughout England and Wales. The resulting selection provides some 247000 findspots to work with (Figure 1a).

A whole range of possible covariate datasets were explored for their possible explanatory potential but the ones that proved to be the most significant predictors in a multivariate, log-linear regression are discussed below ( $\mathrm{p}<0.001$ in all cases).

a) The rough percentage of cropped land in each grid square exhibits a substantial positive correlation with findspot intensities ( $\mathrm{C} 1$ in Figure $1 \mathrm{~b}$ ). We can surmise that this is largely because such areas are regularly ploughed and therefore favoured by metaldetectorists, although it is also possible that these are just generically more active parts of the landscape, regardless of time period and hence produce more finds as a matter of course.

b) The presence of largely free-draining, often lime-rich and not especially acidic soils exhibits a further substantial positive correlation with findspot intensities (the redbrown classes in Figure 1d). At present it is difficult to unpick the possible causes of this correlation but three possibilities spring to mind. Such soils: i) are often more fertile, have seen greater human activity in the past and hence have more finds; ii) are particularly encouraging for successful metal-detecting because, for example, they offer favourable conductivity properties; and/or iii) are geochemically more likely to preserve metal finds in the topsoil.

c) The distance from each grid square to the nearest medium- or small-sized town exhibits a negative correlation with findspot intensities, implying greater odds of metal detector finds close to such areas ( $U$ in Figure $1 b$ but without the eight largest areas). The fact that excluding the largest urban centres offers a better predictor makes intuitive sense

(C) Antiquity Publications Ltd. 
a.
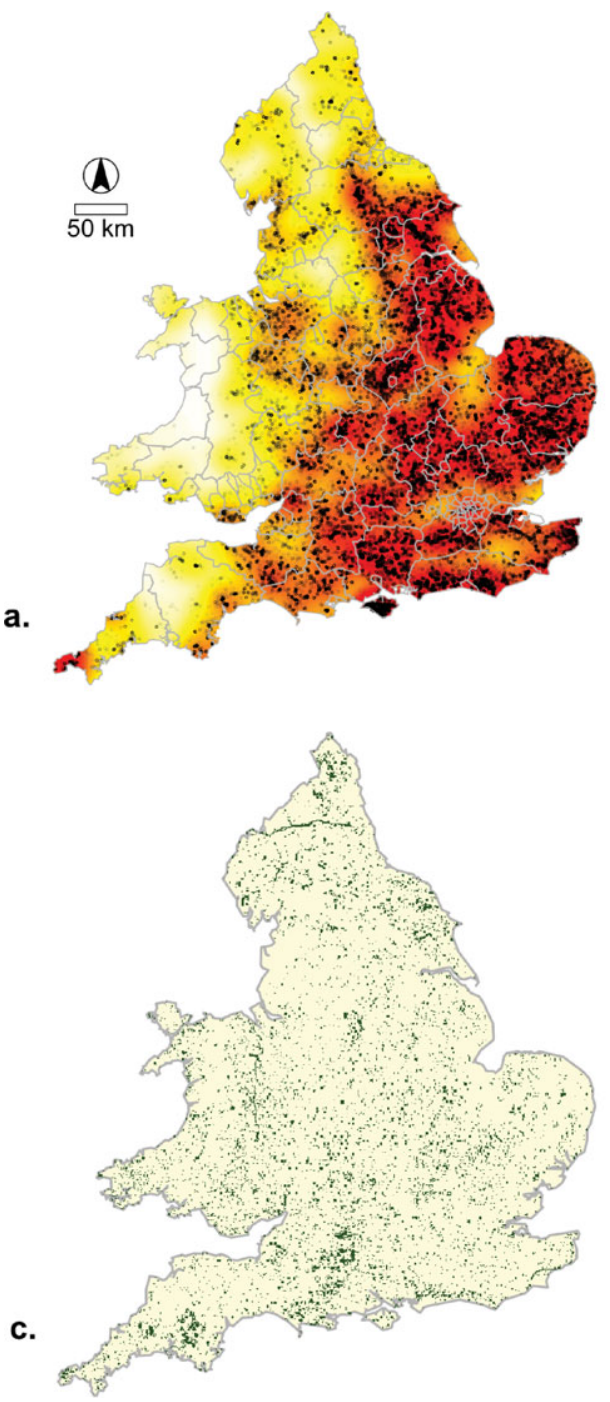

b.

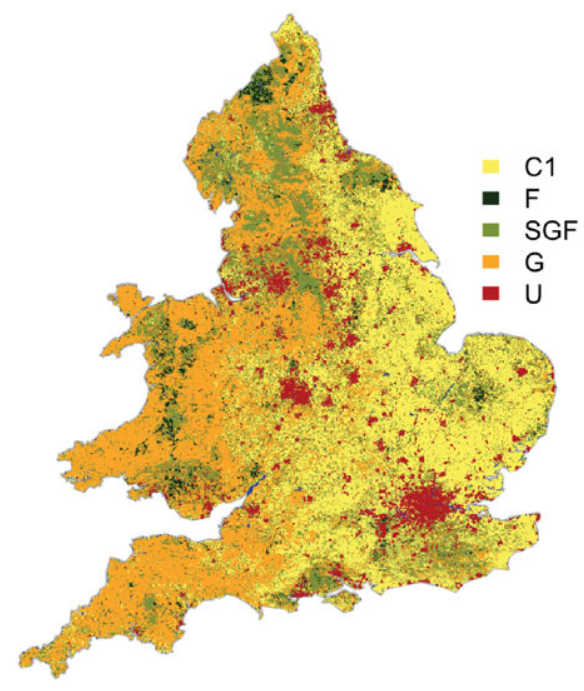

d.

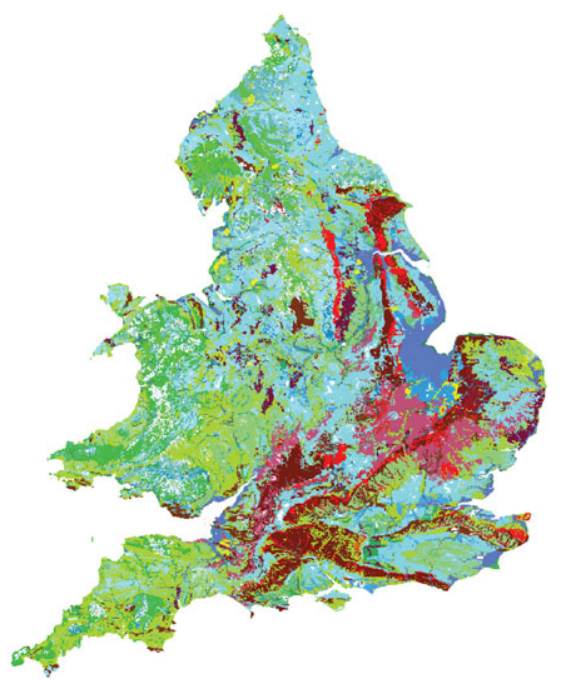

Figure 1. PAS data and selected covariate datasets: a) a weighted kernel density surface of the metal detector finds recorded by the PAS between 2003 and 2011 (Gaussian kernel, $\sigma=10 \mathrm{~km}$; white-yellow-red colours are low to high densities in quantile breaks, with the actual findspots overlaid as black dots); b) major biomes in 2009. The codes are: $C 1=$ cropland $(70-100 \%) ; F=$ closed forest $(>40 \%,>5 \mathrm{~m}) ; S G F=$ mosaic of grassland $(50-70 \%)$ or forest or shrubland (20-50\%); $G=$ closed to open $(>15 \%)$ herbaceous vegetation; $U=$ urban areas $>50 \%$. Other infrequent biome types are present on the map but not shown in the legend; c) Scheduled Ancient Monuments (in green); and d) soil types (the binary classification used in the actual regression model compares the red-brown classes to all others). Source data: PAS; GADM; GlobCover; EH and Cadw ASMs; NATMAPSoilscapes.

given both the likely greater convenience of making day trips within and around small towns, for those who use metal detectors, as well as the substantial earlier phases of human occupation often still present and exposed close to such communities.

(C) Antiquity Publications Ltd. 
d) The distance from each grid square to the nearest Scheduled Ancient Monument exhibits a negative correlation with findspot intensities, implying greater odds of metal detector finds close to such protected zones (Figure 1c shows these monument locations rather than the Euclidean distance surface used in the regression). In the UK, it is illegal for an individual to use a metal detector on a Scheduled Ancient Monument. However, higher frequencies of finds close to such monuments could either be driven by detectorist activity deliberately close by and/or a natural propensity for more finds given the fact that these are usually major sites.

e) A final influential factor on the intensity of PAS finds is absolute spatial location: finds are more likely the further south, and especially the further east, you are in the UK, above and beyond the influence of the other covariates. This suggests that there are further factors at work that are fairly consistent through time and as yet unaccounted for by the other variables, such as: i) the demographic impact of proximity to the European mainland and the latter's metal wealth or, less likely, ii) a more developed tradition of metal-detecting in the south-east.

While the above modelling clarifies and formalises some of the spatial correlations between PAS finds and a range of external environmental affordances, it also poses as many questions as it provides answers. Put simply, it is still sometimes difficult to know whether the observed correlations reflect repeatedly encouraging environments for human activity throughout time, or simply the effect of recovery biases on the PAS dataset (and if the latter, what exact processes). For now, it seems best to remain agnostic about exact causes, given the range of alternatives outlined above, but more detailed work at both a national and a regional scale is clearly worthwhile. There are also residual patterns of clustering of PAS findspots (analysis not shown here), which is probably due to the fact that: a) metal-detecting is usually done on clumps of fields where landowner permission is available, b) individual detectorists have favoured areas, c) metal-detecting rallies encourage concentrated patches of investigation, and d) the archaeological finds themselves often clusters in space, in the form of larger sites. Again it is at present difficult to tease out these different impacts but well worth doing so in future at a more regional scale.

\section{Population surfaces and early Anglo-Norman coinage}

The next two sections move on to consider some methods for making effective practical use of such inventories despite the above recovery problems. One extremely useful approach to any period-specific, large-scale artefact inventory is to assess it against some estimate of the geographical distribution of contemporary population, derived from either historical censuses, or from rough archaeological proxies such as sized settlement distributions or radiocarbon surfaces (for the latter, see Collard et al. 2010). As an example, Figure 2 makes use of the Domesday records by place name and manor across England to build a hypothetical population surface (for the concept of such surfaces see Martin 1996, and for Domesday geographies, see Darby et al.1962-1975). A very simple multiplier of 4.75 has been used to convert all recorded individuals in Domesday to hypothetical household complements and this then allows for the further addition of certain urban populations (C) Antiquity Publications Ltd. 
ignored in Domesday but estimated from other records (following Moore 1997). The implied total across the area shown in Figure 2 is 1.35 million people, which accords well with existing suggestions, as long as we bear in mind that: a) the suggested family size is at best a guess, and b) that the overall population total still underestimates priestly communities, elite households and those in sub-tenancies, as well as excluding the northernmost English counties entirely (Moore 1997; Hinde 2003: 15-21; see also Roffe's more extreme view [2007: 229-33] that larger groups were under-represented because they were not taxable). Despite these caveats, such a surface picks out very clear regional patterns including the high populations in eastern Kent, the Sussex coast, East Anglia, Lincolnshire and the southern Midlands, as well as the growing importance of London. In contrast, the dramatic depopulation and wastage brought about by William I's 'harrying of the North' is obvious, with its severest effects in Yorkshire, but also with an apparent impact as far south as Shropshire (Palmer 1998). Likewise, some regularly low-density parts of the country such as the Weald, the Fens, the New Forest and the moorlands of the far south-west are obvious.

The Corpus of Early Medieval Coin Finds (EMC) records single discoveries across the $\mathrm{UK}$, and at the time of writing, comprises a database of over 10400 coins for the period $\mathrm{AD}$ 410-1180 (or 55000 if the hoard finds from the related online Sylloge of Coins of the British Isles is included). The advantage of considering single finds rather than hoards is that the former are much more likely to express general demographic and economic trends, as they have a greater chance of having been lost by accident in places where they were in frequent use (Blackburn 2005). Where available, a four-figure grid reference for the findspot allows for locations to within either the local parish or the nearest square kilometre. Hence, this dataset is particularly useful at the national or macro-regional scale adopted here, but becomes less spatially-informative for very small-scale studies. For the example below, all non-hoard coin finds from the reigns of William I, William II, Henry I and Stephen (AD 1066-1158) have been included and supplementary data from the PAS has been added where possible (excluding obvious overlaps, for a total of 1444 with valid locations). These coins are silver pennies that were produced in substantial quantities and minted at a fairly wide number of centres across the country (Metcalf 1998). Figure 3 presents their distribution in a similar fashion to the population surface in Figure 2. Comparing the one with the other, there is a very clear global association. Some regions, however, are interesting in departing from the overall match: in particular, the south-west (especially Devon, western Dorset and western Somerset) seems under-represented by coins given the numbers of people said to be living there, while the north-east seems to get more coinage than the Domesday population might predict, which suggests perhaps a resurgence of the Europe-facing parts of the north in the years after Domesday. Overall, however, there also appear to be similar recovery effects to the PAS data (e.g. to do with preferential rediscovery of coins on ploughed land and specific soils) even though the EMC datasets was not collected in exactly the same way.

It is also clear, comparing Figure 1a (all PAS metal finds of all periods) with Figure 2 (late eleventh-century AD population), that human activity in England and Wales has distributed itself in some repeatedly consistent ways over time. For artefact classes such as coins that strongly reflect wider socio-economic networks, the impact of proximity to the European continent is repeatedly clear and probably relates both to the movement of people and to 


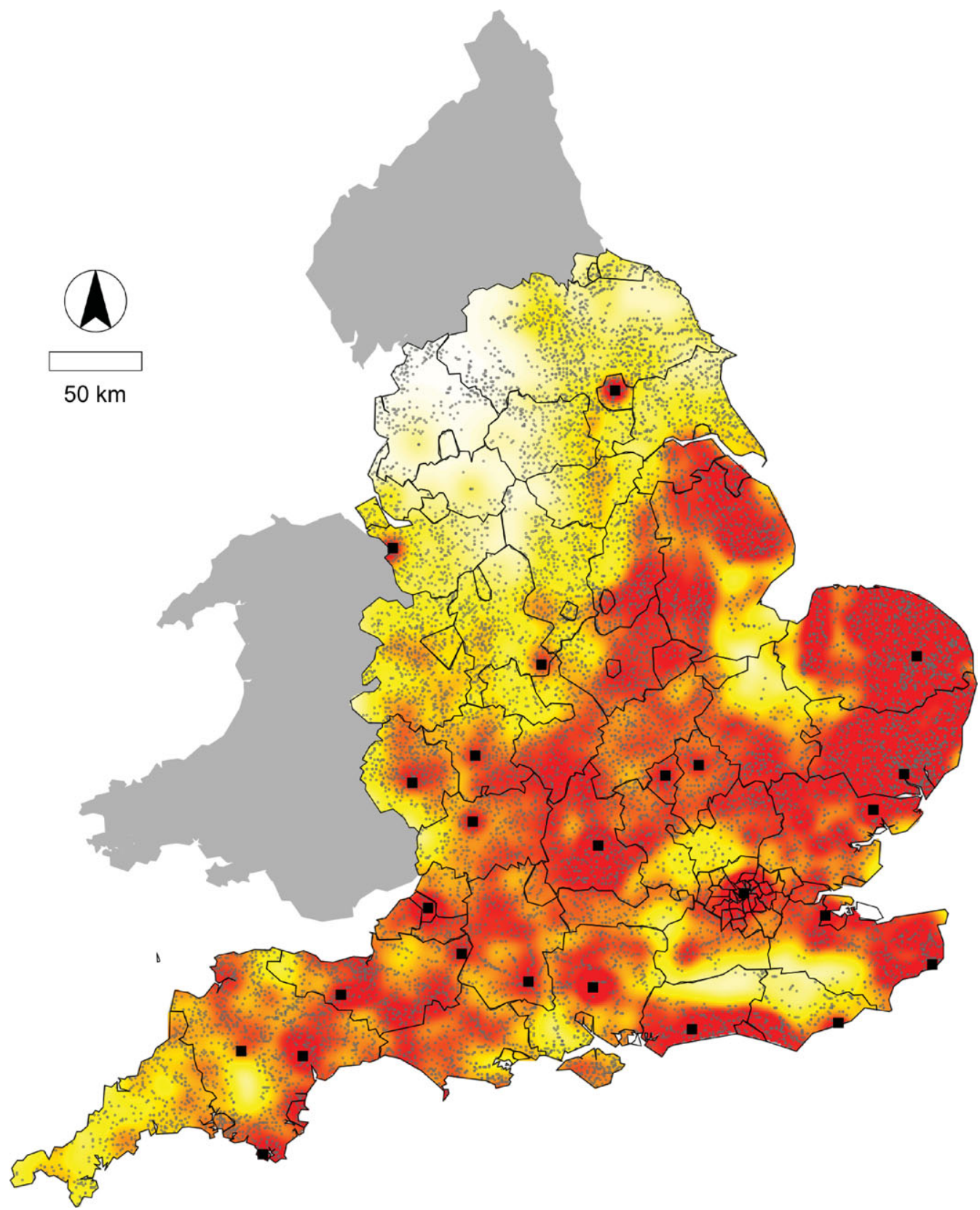

Figure 2. Approximate population densities in AD 1086. The small grey dots are Domesday census points (place names and manors). The underlying heat map is a weighted kernel density shown with quantile breaks (continuous Gaussian kernel, $\sigma=5 \mathrm{~km}$ ). Towns that were absent from Domesday but whose additional urban populations have been estimated based on other documentary evidence are shown as black squares. Modern county boundaries are overlaid for orientation. Source data: ESDS Archive SN 5694; Moore 1997; GADM.

(C) Antiquity Publications Ltd. 


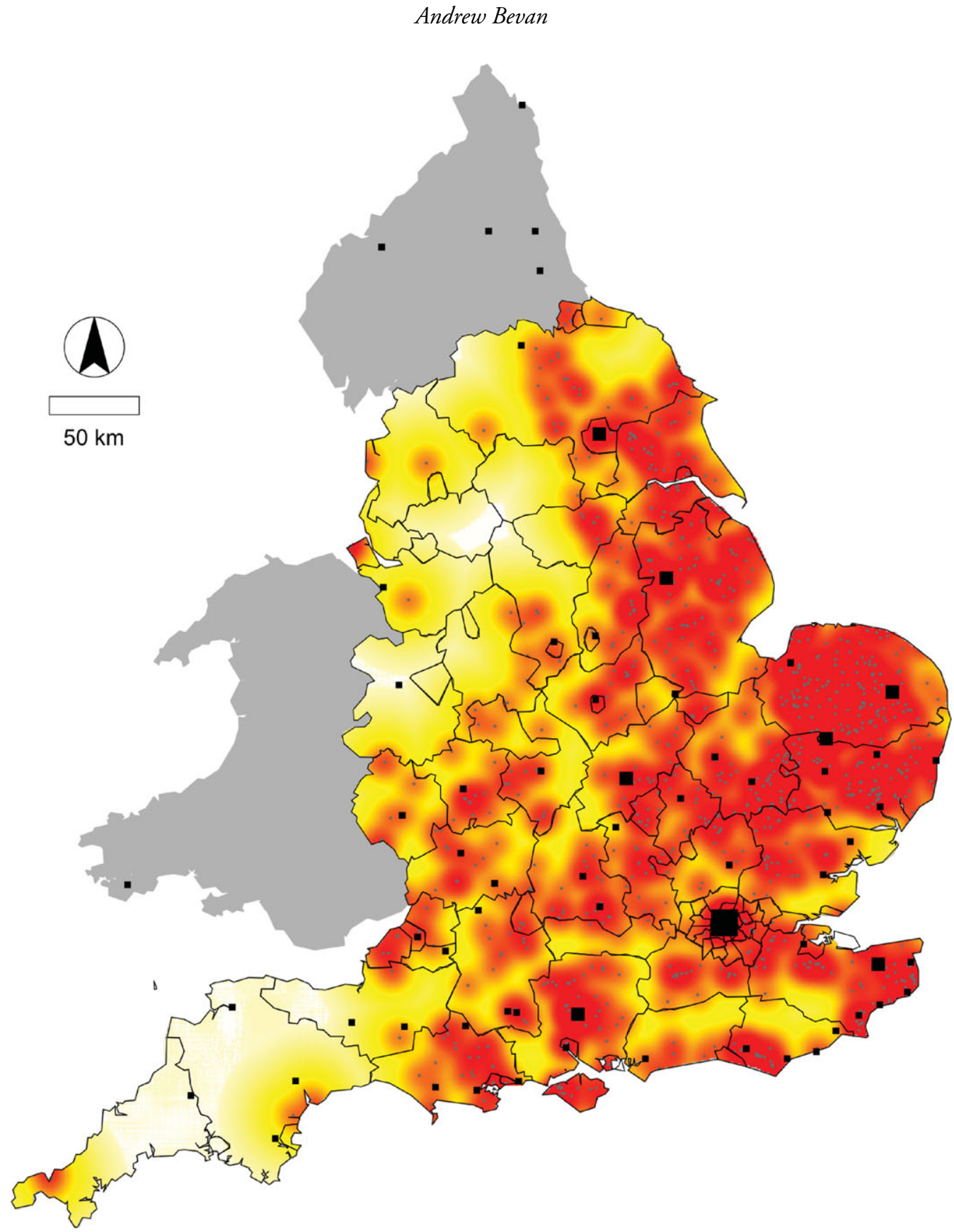

Figure 3. Findspots of early Anglo-Norman coins. The small grey dots are individual findspots and the underlying heat map is a kernel density surface shown with quantile breaks (continuous Gaussian kernel, $\sigma=5 \mathrm{~km}$ ). London and other major and minor mints are shown as black squares in three sizes. Modern county boundaries are overlaid for orientation. Only single coin finds in the areas overlapping with the Domesday data in Figure 2 are shown. Source data: EMC; GADM.

(C) Antiquity Publications Ltd. 
a westwards flow of continental bullion that underpinned the English money supply (e.g. Allen 2011).

\section{Relative risk surfaces and Late Iron Age coinage}

The Domesday example above is interesting because it brings together a distribution of underlying demography and one for a specific set of artefacts (contemporary coinage) and makes it possible to explore global consistencies and local variations. Both this example and the first section's study of recovery bias also reinforces the weakness of merely considering a straightforward distribution of cultural material, as this is strongly effected by: a) variation in post-depositional preservation and modern recording, b) a spatially-varying density of past users, as well as c) those culturally-mediated processes responsible for finally trapping artefacts in the ground.

Faced with these challenges, one approach is to try to model the recovery biases affecting each distribution in an exhaustive way (starting from the types of correlative model developed for all PAS finds above) and then use the result to de-trend actual, observed patterns of recovery. However, it is likely that, in many cases, such a complicated approach is doomed to failure and, instead, an effective alternative is to adopt a form of ratio-based (or more formally, case control) mapping known as a 'relative risk' surface (Kelsall \& Diggle 1995). Such relative risk surfaces are increasingly common in disciplines such as epidemiology where proper assessment of the factors effecting raw numbers of cases (e.g. of flu virus) can be confounded by variations in the underlying population (i.e. those potentially at risk) and/or variable recording. Put simply, relative risk surfaces involve calculating the ratio of the kernel density estimation of the observed cases of a particular type to that of the at-risk population, and significance tests for such surfaces are also possible (Hazelton \& Davies 2009).

There are various ways in which such surfaces can be used with the PAS or other inventories and part of the challenge often becomes the appropriate definition of the at-risk population. As a regional example, the discussion below returns to one of the most well known and often revisited case studies in using numismatic evidence to understand patterns of political geography and ethnic identity: Late Iron Age coinage in southern Britain with, in this case, a particular focus on the south-west. During the Iron Age, the latter region becomes covered in hillforts with important intermediary roles within longer-range, trans-isthmian and/or riverine networks (Sherratt 1996). Local coinage in gold, silver and copper alloys develops from the first century BC to the first century AD due to the impact of coinage from Gaul, and ultimately due to economic interdependencies with, and the sheer mass of contemporary coin circulating in, the Mediterranean world. The main period of interest for this paper is one of about 80-100 years after the arrival and use of the first Gallic coins, but before the Roman conquest of AD 43 (Haselgrove 1993: especially periods 6-9).

Despite the very careful recording efforts reflected in the Celtic Coin Index (CCI), many problems of recovery and patchy investigation remain, not least because it reflects an amalgam of finds from excavations, metal detectors and other chance discoveries, and because there are still some remaining issues with the way CCI has been integrated with the PAS. It is also increasingly clear that Iron Age coins ended up in the archaeological record (C) Antiquity Publications Ltd. 

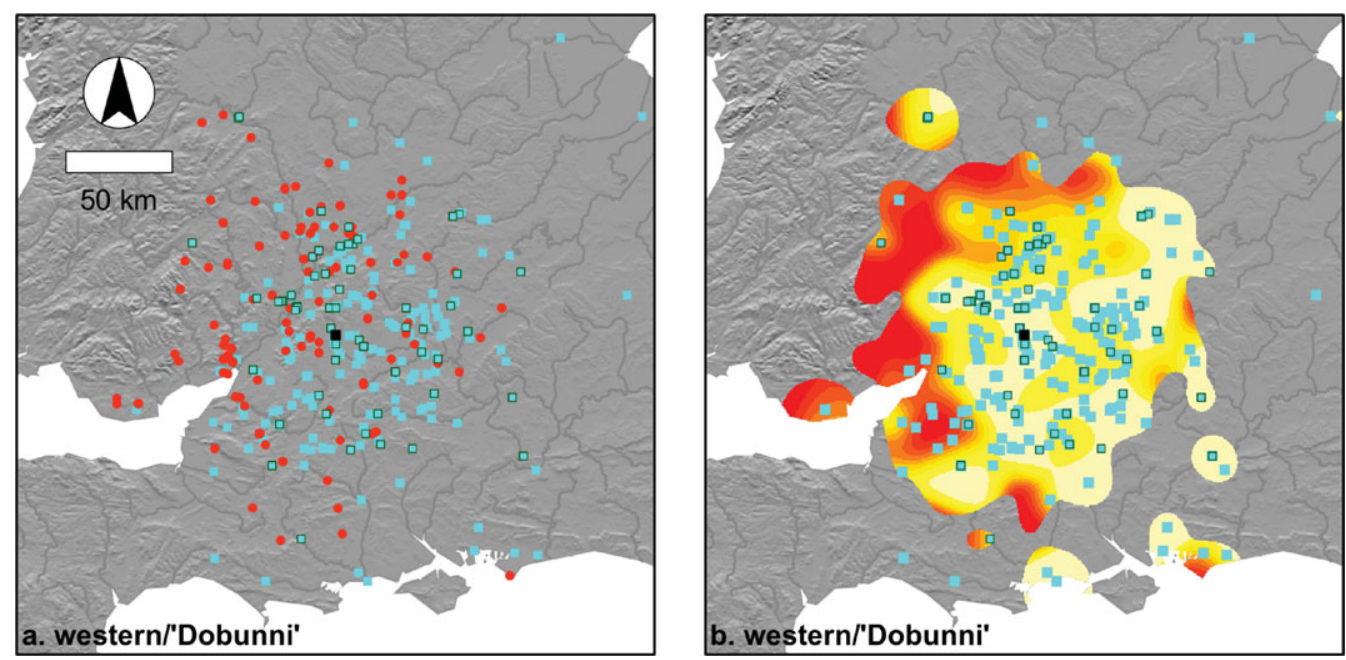

Figure 4. Plots of Late Iron Age coins attributed to production in what later became the Dobunnic canton: a) a standard distribution map disaggregating coins by gold as red circles and silver as blue squares (some 'Dobbuni' coins labelled as copper alloy in the PAS database are typically very debased silver and are shown with a green outline); b) the same plot, but with the gold coins now expressed as a relative risk surface (truncated along its edges at an arbitrary minimum findspot density). Source data: CCI/PAS, NASA/CGIAR SRTM and CCM.

due to widespread hoarding and votive offering, often for ritual purposes (Haselgrove \& Wigg-Wolf 2005; also Rodwell 1981), and that this may not be an accurate reflection of the full spectrum of their use-life above ground (in contrast, the situation for the medieval coins considered above is usually thought to be more straightforward). In any case, Figure 4a considers a distribution of coins that are found in gold and silver of different denominations but that are all plausibly associated with production by Iron Age communities in a region that would later become the Roman canton of the 'Dobunni'. The distribution in Figure 4a suggests a clear focus for western/'Dobunni' style coinage around the eastern side of the Severn Valley, with a centre of gravity very close to present-day Cirencester and the remains of a large Iron Age hillfort at Bagendon (Clifford 1961). While recent finds of coin moulds at several different locations in the broad region argue against a single mint and point source for such coinage, it nonetheless seems plausible to consider Bagendon and its surrounds as the core of a Late Iron Age political territory covering up to a $1000 \mathrm{~km}^{2}$. Many commentators have noted this attractively clear-cut distribution and sought to use it to delineate the exact boundaries of a pre-conquest tribal area (e.g. Allen 1961; Hogg 1971; Kimes et al. 1982; Selwood 1984; Cunliffe 1991; Van Arsdell 1994), with varying degrees of success.

One intuitive conclusion that we might draw from informal assessment of Figure $4 \mathrm{a}$ is that the respective spatial distributions of gold and silver coins of 'Dobunnic' type overlap but are not identical, evoking potentially different spheres of exchange (Collis 1971: 7679). Overall, Iron Age gold coinage is unusually common in hoards when compared with later Roman period hoard compositions, for example (Bland \& Loriot 2010: 28-29). Also, the designs on Iron Age gold coins adhered to more conservative stylistic traditions than contemporary silver ones, often suggesting linkages to kings, kingly retinues, horses and the other-worldly (especially Creighton 2005: 78-80). With these possible distinctions in

(C) Antiquity Publications Ltd. 

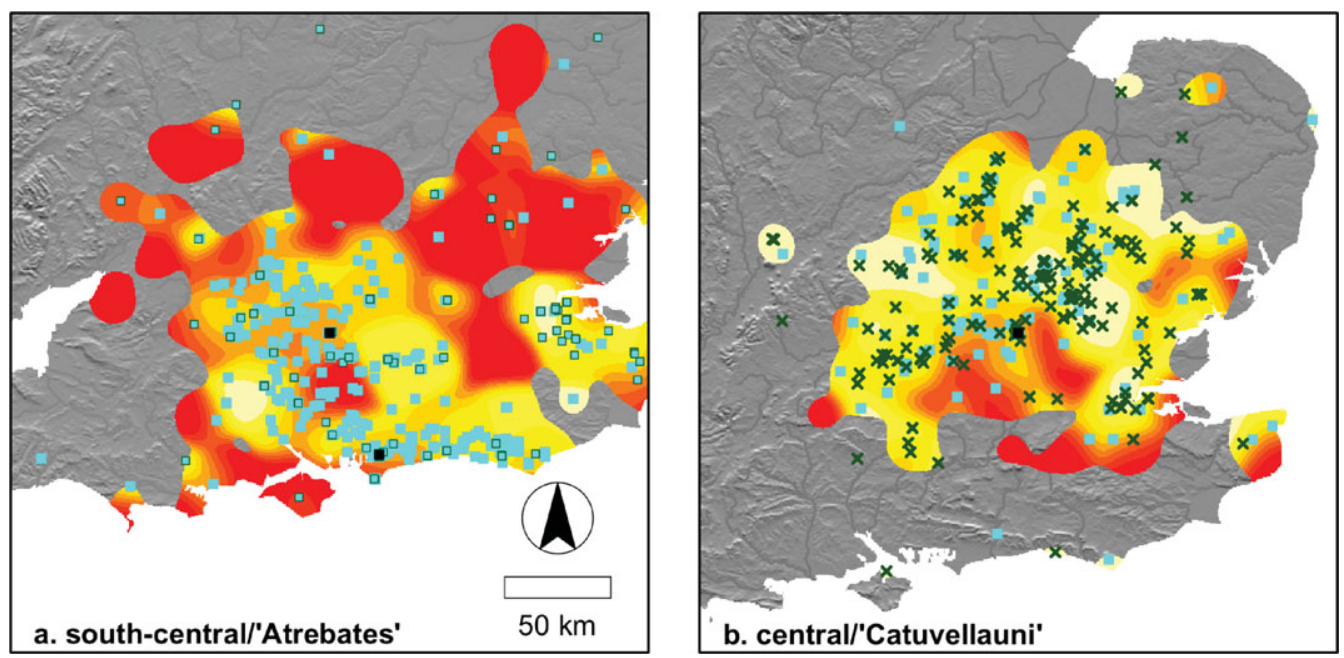

Figure 5. Relative risk surfaces for gold issues attributed to: a) south-central/Atrebates' tribal areas; and b) the eastcentral/'Catuvellauni' (Tasciovanus, 'ANDOCO', 'DIAS' and 'RVES' inscribed issues only). Silver coins are overlaid as cyan squares (some 'Atrebates' coins labelled as copper alloy in the PAS database are typically very debased silver and are shown with a green outline), and copper alloy coins as green crosses. For the relative risk surface, from yellow to red colours implies from low to high risk of gold coins. Source data: CCI/PAS, NASA/CGIAR SRTM and CCM.

mind, we can revisit the regional distribution of gold versus silver coins via a relative risk surface. Figure $4 \mathrm{~b}$ offers an example of such a surface and confirms our initial impression that the odds of finding gold coinage of 'Dobunnic' type rather than silver ones are lower in the centre of the overall 'Dobunnic' distribution and significantly higher on the western, Welsh side. Note that while some might suggest that Figure $4 \mathrm{~b}$ does not add very much that cannot be seen in Figure 4a, this is not so, as the former makes it possible to account for relative odds in any possible hoards or superimposed findspots that are otherwise very hard to visualise correctly. If we turn to similar plots for two other regional styles of coinage, the same overall pattern is visible (Figures $5 \mathrm{a}-\mathrm{b}$ ). The odds of finding coinage issued by a particular tribe in gold are typically far higher on the edges of the distribution for those regional types. Moreover, there is the impression that in some cases, the flow of gold to the periphery is demonstrably directional: north and westwards for 'Dobunni' gold coin, and southwards for the 'Catuvellauni', perhaps indicating some quite specific relationships with neighbouring tribes. These surfaces clearly gloss over some problems of attribution (e.g. de Jersey 2007) and some important political and economic developments over 100 years. For example, variability in the 'Atrebates' area between the major sub-centres of Silchester and Chichester is already suggested by the donut-shaped relative risk surface in Figure 5b. These might be investigated further by considering individual coin issues (see Leins n.d) or shorter timespans. As an example of the latter, Figure $5 \mathrm{~b}$ deliberately restricts its analysis to only those coins inscribed for issuers in the central/'Catuvellauni' area over a few decades to either side of 0 BC (Tasciovanus, 'ANDOCO', 'DIAS', 'RVES'; Haselgrove 1993: period 7), and again, there is a distinct pattern involving different kinds of monetary flow for gold versus other metals.

(C) Antiquity Publications Ltd. 

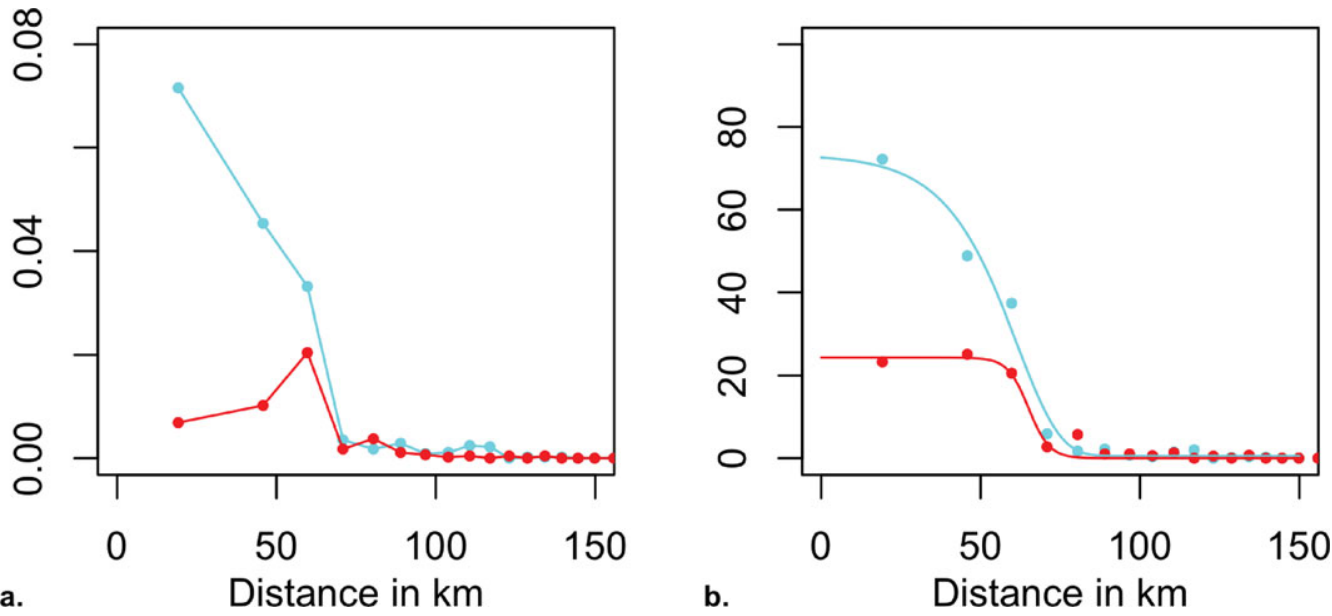

Figure 6. Fall-off curves for gold versus silver coins of 'Dobunni' type: a) the density per square kilometre of gold (red) versus silver (cyan, including very debased silver) as a function of increasing distance from Bagendon; and b) the proportion of gold or silver coins that are of 'Dobunni' type as a function of increasing distance from Bagendon. Source data: CCI/PAS, NASA/CGIAR SRTM and CCM. Each datapoint represents a sample area of equal size, and for the second plot, negative logistic fall-off models have been fitted by maximum likelihood methods.

Finally, most previous studies have wrestled with the issue of whether raw densities of Late Iron Age coin finds could be used as indicators of frontier zones between tribal areas (e.g. Hogg 1971; Hodder \& Orton 1976: 109-114, 196-97; Kimes et al. 1982). The implication of the above relative risk surfaces is that the raw densities of gold coin will give us a rather poor idea of any tribal territory, whilst silver and copper coins will offer a much better impression. Fall-off curves are one traditional way of addressing the question of territoriality (Soja 1971), even if their one-dimensional character will obscure some of the directional effects noticed above. Figures $6 \mathrm{a}-\mathrm{b}$ show two useful ways of expressing fall-off with distance from Bagendon (remembering that we can treat this as the approximate centre of the distribution but not as the only mint site). The first of these fall-off curves (Figure 6a) depicts the changing raw density of gold and silver coins with increasing distance from Bagendon, and here it is clear that the number of silver coins per square kilometre declines sharply with distance, while in contrast, gold coins become temporarily more abundant on the periphery of the distribution before also declining. Figure $6 \mathrm{~b}$ offers a different perspective by considering, for each distance band, all coins in a given material, regardless of the tribe to which they might be attributed. We can then plot the proportion of those that are actually 'Dobunnic' in style with two interesting results. First, it is clear that silver coins are far more likely to be of local design than gold ones in the centre of the tribal area. For example, at least 70 per cent of the silver coin in the first $40 \mathrm{~km}$ away from Bagendon is of 'Dobunni' style (and perhaps more given some unclear examples), in contrast to perhaps 22 per cent of gold coins. Second, and despite this difference in proportions, the fall-off curves of silver and gold are more comparable in shape when treated this way than when expressed as raw densities. The proportions of 'Dobunni' style coins in both materials exhibit similar drop-offs around

(C) Antiquity Publications Ltd. 
50-70 km away from Bagendon and, in formal terms, can be modelled very satisfactorily by a negative logistic function (as shown).

In any case, such analysis adds strength to a model in which use of silver coinage (and also copper, where available) circulated in more deliberately territorialised spheres as part of the everyday workings of the local tribal economy (no doubt supplementing many transactions that involved no coinage at all), while gold coin fulfilled a different role, most likely in the paying of mercenaries, the offering up of tribute to neighbours and consolidation of borderland loyalties (see also de Jersey 2005: 106).

\section{Conclusion}

Today, archaeology is confronted with new opportunities to build the sorts of longitudinal, wide-ranging and multimedia narratives perhaps last common in the days of Gordon Childe. For many years, a combination of the sheer volume of accumulating archaeological information, and the massive barriers facing anyone attempting to collate it across different regions, artefact classes or sub-disciplines, has made certain types of meta-analysis very difficult. However, large-scale, geo-referenced digital datasets now allow archaeology to revisit some long-established agendas. If we are to take significant advantage of these opportunities, then we need to develop approaches that not only expose continuing biases present in such data but also move well beyond them. This paper suggested some formal ways by which this might be possible, emphasising: a) careful consideration of recovery effects via regression models, b) comparisons between artefact distributions and proxies for the historical distribution of people, and c) the use of relative risk surfaces or similar techniques to identify interesting spatial patterns even when the data is patchy, and especially when breaking down patterns by sub-classes of material. None of this, of course, is to suggest that we should stop paying careful attention to archaeological context or the details of specific artefacts, only that we are now in a position to combine these with much broader perspectives in new and potentially more satisfying ways.

\section{Acknowledgements}

My particular thanks to Daniel Pett for his work on the Portable Antiquities Scheme database (PAS, http://finds.org.uk/, now including the Celtic Coin Index) and for granting me full access to it. The datasets and software used in this paper are:

Domesday Book (http://www.esds.ac.uk/findingdata/sndescription.asp?sn=5694)

Corpus of Early Medieval Coin Finds (EMC) (http://www-cm.fitzmuseum.cam.ac.uk/emc/)

English Scheduled Ancient Monuments (http://services.english-heritage.org.uk/NMRDataDownload/)

Welsh Scheduled Ancient Monuments (Cadw, on request)

GADM (http://www.gadm.org/)

GlobCover 2.3 (http://ionia1.esrin.esa.int/)

CGIAR-SRTM (http://srtm.csi.cgiar.org/)

Catchment Characterisation and Modelling Database (http://ccm.jrc.ec.europa.eu/php/index.php?action= view\&id=23)

NATMAPSoilscapes (http://www.landis.org.uk/data/natmap.cfm)

R (http://www.R-project.org/) with the spatstat package (Baddeley \& Turner 2005)

(C) Antiquity Publications Ltd. 
The following people were also very helpful in offering advice, facilitating access or commenting on drafts: Martin Allen, Roger Bland, Stuart Brookes, Nigel Davies, Tilman Davies, Timothy Farewell, Robert Hijmans, Ian Leins, Kris Lockyear, John Moore, John Palmer, Anna Powell-Smith and Rolf Turner. I am also grateful to the journal editor and anonymous reviewers for a range of useful comments.

\section{References}

Allen, D. 1961. A study of the Dobunnic coinage, in E. Clifford (ed.) Bagendon: a Belgic oppidum: 75-149. Cambridge: Heffer and Sons.

Allen, M. 2011. Silver production and the money supply in England and Wales, 1086-c.1500. Economic History Review 64(1): 114-31.

BADDELEY, A.J. \& R. TURNER. 2005. spatstat: an R package for analyzing spatial point patterns. Journal of Statistical Software 12(6): 1-41.

BEVAN, A. In press. Value, authority and the open society. Some implications for digital and online archaeology, in C. Bonacchi (ed.) Archaeology and digital communication: towards strategies of engagement. London: Archetype.

BLACKBURN, M. 2005. Disseminating find evidence; the British Corpus of Early Medieval Coin Finds, in C. Alfaro, C. Marcos \& P. Otero (ed.) XIII Congreso Internacional de Numismática I: 169-71. Milan: Ministerio de Cultura, Secretaría General Técnica.

BLAND, R. 2005. Rescuing our neglected heritage: the evolution of the Government's policy on Portable Antiquities and Treasure. Cultural Trends 14(4): 257-96.

Bland, R. \& X. LORIOT. 2010. Roman and Early Byzantine gold coins found in Britain and Ireland. London: Royal Numismatic Society.

BrIndLe, T. 2011. The Portable Antiquities Scheme and Roman Britain. Unpublished PhD dissertation, King's College London.

Clifford, E. (ed.) 1961. Bagendon: a Belgic oppidum. Cambridge: Heffer and Sons.

Collard, M., K. Edinborough, S. Shennan \& M.G. THOMAs. 2010. Radiocarbon evidence indicates that migrants introduced farming to Britain. Journal of Archaeological Science 37: 866-70.

Collis, J.R. 1971. Functional and theoretical interpretations of British coinage. World Archaeology 3(1): 71-84.

Creighton, J. 2005. Gold, ritual and kingship, in C. Haselgrove \& D. Wigg-Wolf (ed.) Iron Age coinage and ritual practices: 69-84. Mainz am Rhein: Philipp von Zabern.

Cunliffe, B. 1991. Iron Age communities in Britain. London: Routledge \& Kegan Paul.

Darby, H.C., E.M.J. Campbell, I.S. MaXwell, I.B. Terrett, G.R. Versey \& R. Welldon FinN (ed.). 1962-1975. Domesday geography of England. Cambridge: Cambridge University Press.
DE JERSEY, P. 2005. Deliberate defacement of British Iron Age coinage, in C. Haselgrove \& D. Wigg-Wolf (ed.) Iron Age coinage and ritual practices: 85-113. Mainz am Rhein: Philipp von Zabern.

-2007 . Evidence of absence? The rarity of gold in Durotrigan Iron Age coinage, in C. Gosden, H. Hamerow, P. de Jersey \& G. Lock (ed.) Communities and connections: essays in honour of Barry Cunliffe: 367-86. Oxford: Oxford University Press.

Haselgrove, C. 1993. The development of British Iron Age coinage. Numismatic Chronicle 153: 31-63.

Haselgrove, C. \& D. WigG-Wolf (ed.). 2005. Iron Age coinage and ritual practices. Mainz am Rhein: Philipp von Zabern.

Hazelton, M.L. \& T.M. Davies. 2009. Inference based on kernel estimates of the relative risk function in geographical epidemiology. Biometrical Journal 51(1): 98-109.

Hinde, A. 2003. England's population. A history since the Domesday survey. London: Hodder Arnold.

HodDER, I. \& C. ORTON. 1976. Spatial analysis in archaeology. Cambridge: Cambridge University Press.

HoGG, A.H.A. 1971. Some applications of surface fieldwork, in M. Jesson \& D. Hill (ed.) The Iron Age and its hillforts: 105-125. Southampton: University of Southampton.

Kelsall, J.E. \& P.J. Diggle. 1995. Non-parametric estimation of spatial variation in relative risk. Statistics in Medicine 14: 2335-43.

Kimes, T., C. Haselgrove \& I. Hodder. 1982. A method for the identification of the location of regional cultural boundaries. Journal of Anthropological Archaeology 1: 113-31.

LEINS, I. n.d. Numismatic data reconsidered: coin distributions and interpretation in studies of Late Iron Age Britain. Unpublished PhD dissertation, University of Newcastle.

MarTiN, D. 1996. An assessment of surface and zonal models of population. International Journal of Geographic Information Science 10(8): 973-89.

MetCalf, D.M. 1998. An atlas of Anglo-Saxon and Norman coin finds, c. 973-1086 (RNS Special Publication 32). London: Royal Numismatic Society.

MoOrE, J.S. 1997. 'Quot homines?': the population of Domesday England. Anglo-Norman Studies 19: 307-334. 
Palmer, J.J.N. 1998. 'War and Domesday waste', in M. Strickland (ed.) Armies, chivalry and warfare in medieval Britain and France: proceedings of the 1995 Harlaxton Symposium: 256-75. Stamford: Paul Watkins.

Richards, J.D., J. NaYlor \& C. Holas-Clark. 2009. Anglo-Saxon landscape and economy: using portable antiquities to study Anglo-Saxon and Viking Age England. Internet Archaeology 25. Available at: http://intarch.ac.uk/journal/ issue25/richards_index.html (accessed 3 February 2012).

RoBbins, K. In prep. From past to present: understanding the impact of sampling bias on data recorded by the Portable Antiquities Scheme. Unpublished PhD dissertation, University of Southampton.

RODWELL, W. 1981. Lost and found: the archaeology of find-spots of Celtic coins, in B. Cunliffe (ed.) Coinage and society in Britain and Gaul: some current problems: 43-52. London: Council for British Archaeology.

Roffe, D. 2007. Decoding Domesday. Woodbridge: Boydell.

SELWOOD, L. 1984. Tribal boundaries viewed from the perspective of numismatic evidence, in B. Cunliffe $\&$ D. Miles (ed.) Aspects of the Iron Age in central southern Britain (Oxford University Committee for Archaeology Monographs 2): 191-205. Oxford: Oxford University Committee for Archaeology, Institute of Archaeology.
Shennan, S.J. \& J. Conolly. 2007. The origin and spread of Neolithic plant economies in the Near East and Europe. UKADS Archive 452. doi: $10.5284 / 1000093$.

SherratT, A. 1996. Why Wessex? The Avon route and river transport in later British prehistory. Oxford Journal of Archaeology 15(2): 211-34.

SOJA, E. 1971. The political organization of space. Washington, D.C.: Association of American Geographers.

Steele, J. \& S.J. Shennan. 2000. Spatial and chronological patterns in the Neolithisation of Europe. UKADS Archive 283. doi: 10.5284/1000207.

VAN ARSDELL, R. 1994. The coinage of the Dobunni (Oxford University Committee for Archaeology Monograph 38). Oxford: Oxford University Committee for Archaeology, Institute of Archaeology.

Verhagen, P. \& T.G. Whitley. 2011. Integrating archaeological theory and predictive modeling: a live report from the scene. Journal of Archaeological Method and Theory. Online First. doi: 10.1007/s10816-011-9102-7.

Walton, P. 2010. Rethinking Roman Britain: an applied numismatic analysis of the Roman coin data recorded by the Portable Antiquities Scheme. Unpublished PhD dissertation, University College London.

Received: 7 September 2011; Accepted: 1 November 2011; Revised: 10 November 2011

(C) Antiquity Publications Ltd. 